\title{
Turismo Rural e Geração de Resíduos Sólidos em Lomba Grande - Novo Hamburgo - RS
}

\author{
Roberto Naime, Sérgio Carvalho
}

\begin{abstract}
RESUMO
Este trabalho realiza um levantamento sobre a geração de resíduos sólidos em propriedades rurais utilizadas por turismo rural, particularmente em finais de semana, no regime de "day use". Os resíduos sólidos encontrados tem composição muito variada, mas predomina a matéria orgânica gerada por restos de alimentos, metais, papéis, plásticos e vidros. As coletas foram realizadas no final de 2007 e início de 2008. A análise permite afirmar que a matéria orgânica guarda correlação direta com o número de pessoas presentes na data da análise e esta diretamente relacionada com restos de alimentos. Os metais representam em geral a quantidade de latas de alumínio para envase de refrigerantes ou cervejas que foi consumida. Os plásticos podem representar restos de sacolas, copos, pratos, garrafas de refrigerantes de Polietileno Tereftalato (PET) e assemelhados. O vidro não está presente porque o sítio São Luiz não permite a entrada deste tipo de vasilhame. Todos os turistas das datas onde foram realizados os levantamentos pertenciam a grupos religiosos. A geração de matéria orgânica é relacionada diretamente ao número de turistas, idade dos turistas e ao cardápio servido aos turistas na propriedade. A propriedade rural estudada aplica um programa de gerenciamento dos resíduos sólidos.
\end{abstract}

PALAVRAS-CHAVE: Turismo Rural, Resíduos Sólidos, Gestão

Rural Tourism and Generation of Solid Waste in Lomba Grande - Novo Hamburgo - RS, Brazil

\section{ABSTRACT}

This paper presents a survey on the production of solid waste in rural properties used for rural tourism, particularly on weekends, in a "day use" regime. Solid waste composition found was very diverse, but the organic matter generated by the remains of food, metals, paper, plastics and glass overcame. The collection of data was made late 2007 and early 2008 . The analysis show that the organic matter maintains direct correlation with the number of people present at the time of the analysis and is directly related to the remains of food. The metals were generally represented by the amount of soft drink or beer aluminum cans that were consumed. Plastic may be represented by the remains of bags, glasses, dishes, polyethylene terephthalate bottles (PET) and similar. The glass is not present because the farm "São Luiz" does not permit the entry of this type of packaging. All tourists, from when the surveys were carried out, belonged to religious groups. The production of organic matter is directly related to the number of tourists, their ages and the menu served on the property. The rural property study executes a management program for solid waste.

KEYWORDS: Rural Tourism, Waste, Management 


\section{INTRODUÇÃO}

\section{Turismo como atividade sustentável}

A produção de bens e serviços que atendam às necessidades e aos desejos humanos requer recursos ou fatores de produção, dos quais o trabalho e os recursos naturais sempre estiveram presentes em todas as épocas. O capital entendido como meio de produção, criado pelo trabalho humano para produzir outros bens e serviços aparece tardiamente na história da Humanidade.

Os recursos naturais são bens e serviços originais ou primários dos quais todos os demais dependem. Assim, pode-se dizer que produzir é converter ou transformar bens e serviços naturais para satisfazer as necessidades e os desejos humanos. Os recursos naturais, geralmente denominados Terra nos textos de Economia, envolvem elementos ou partes do meio ambiente físico e biológico, como solo, plantas, animais, minerais e tudo o que possa ser útil e acessível à produção da subsistência humana.

A idéia da sustentabilidade sob a ótica do desenvolvimento nasceu em resposta à falta de equilíbrio entre as propostas desenvolvimentistas tradicionais e o uso dos recursos naturais. Em sua essência, a reflexão do conceito propõe um caminho alternativo entre a economia convencional e as práticas de desenvolvimento, um caminho que não pode ser medido apenas através dos índices de produtividade do sistema capitalista tradicional. As avaliações relacionadas à obtenção de sustentabilidade são cada vez mais direcionadas a um modelo de crescimento econômico em função do bem-estar das comunidades e da conservação do meio ambiente (ZIMMERMAN, 2000).

O turismo está entre os segmentos que têm apresentado maiores taxas de crescimento na economia mundial: telecomunicações, informática, turismo, química fina e biotecnologia. Atualmente, a atividade turística oscila entre o $2^{\circ}$ e $03^{\circ}$ segmento de maior movimentação econômica em escala mundial. O turismo emprega 250 miIhões de pessoas em todo o planeta, e é o maior gerador de receitas de impostos, equivalendo atualmente a US\$ 802 bilhões de dólares. É a maior indústria do mundo em termos de produção bruta, que passa dos US\$3,4 trilhões de dólares (ASHTON e BALDISSERA, 2003). Os números mostram a importância do turismo para o mundo, principalmente, como gerador de trabalho e renda, e sua importância para o desenvolvimento econômico, político, social e cultural da sociedade envolvida.

O turismo tem a capacidade de abranger diversos segmentos econômicos de uma região, relacionando-se com diversas atividades produtivas. Esta conexão entre vários setores poderá resultar no desenvolvimento econômico articulado na região turística. A infra-estrutura local de rodovias, sistemas de água e esgoto, telecomunicações e outras pode ser, e em geral é, otimizada através do desenvolvimento do turismo, o que traz benefícios econômicos e ambientais. Embora este seja um benefício mais subjetivo, o desenvolvimento de instalações turísticas bem projetadas pode promover melhorias em paisagens naturais ou urbanas que, de outra forma, podem apre- 
sentar-se tediosas e desinteressantes.

O efeito multiplicador da atividade turística permite afirmar que o turismo pode representar uma excelente alternativa para o desenvolvimento tanto local quanto regional, preservando a identidade local e conservando os patrimônios natural e cultural, alem da dinamização que produz na economia das cidades.

Entretanto, diante desse contexto, não tem sido dada à devida importância aos segmentos ambiental, cultural e social, resultando em impactos negativos. A segmentação do turismo vem ocorrendo para atender às diferentes demandas, que têm solicitado produtos turísticos diferenciados, fazendo surgir diversos tipos de turismo. Observa-se em quase todos os segmentos a repetição dos mesmos erros em planejamento, em gestão e na operacionalização, seja político-setorial e/ou estrutural. Creditam-se muitas falhas não somente ao interesse econômico, mas, em parte, ao desconhecimento de como se formar os produtos turísticos a partir dos atrativos da natureza. É muito comum se adotar os mesmos procedimentos como se fossem no meio urbano, resultando em produtos descaracterizados, consumidos de forma crescente e desordenados em ecossistemas diversificados, importantes e frágeis.

O crescimento dessa atividade precisa observar ações voltadas para o meio ambiente, apresentando políticas de desenvolvimento em prol do mesmo, induzindo os trabalhos e a consciência dos turistas para a preservação da flora e fauna; para a comunidade, de forma que economicamente ocorram melhorias, porém não se perca a identidade local; a integração do turista com o nativo deve acontecer positivamente, e não acarretar o desejo do nativo em possuir o que o turista tem e vice-versa.

O termo turismo sustentável foi proposto, segundo Ruschmann (2000, p.70), "para evitar os riscos que a condução inadequada da atividade pode provocar no meio ambiente", considerando ainda os habitantes locais e os visitantes, além dos prestadores de serviços. O turismo pode ajudar a justificar e a pagar pela preservação de parques naturais, recreações ao ar livre e manutenção de áreas como atrações que de outra forma, podem ser deterioradas ecologicamente. Além disso, a interação da Educação Ambiental com o turismo aprofunda a análise do espaço, demonstrando de que maneira a ação antrópica interfere nos processos modificadores do ambiente causando o seu desequilíbrio. Quando o turista passa a conhecer o espaço, cria-se uma identidade com o meio ambiente promovendo sua valorização, afinal só se preserva o que se conhece.

Para o turismo sustentável, mais importante do que o próprio turismo é a preservação do meio ambiente, a inserção social dos residentes, a geração de renda e a melhoria da qualidade de vida, de tal forma que o local suporte, o contato e uso do ser humano e, ao mesmo tempo, mantenha-se para que as gerações futuras também possam dele usufruir (SWARBROOKE, 2000).

Para ser realmente sustentável, o turismo precisa ir ao encontro às necessidades da população anfitriã de forma que produza melhores padrões de qualidade de vida, tanto a curto como em longos prazos; satisfaça as demandas de crescimento da 
quantidade de turistas e continue a atraí-los de uma forma que se mantenha o atendimento das necessidades da população local; e proteja o meio ambiente de maneira que se atinjam os dois objetivos anteriores, ou seja, o de manter a satisfação dos visitantes e conseqüentemente, atender às necessidades das populações locais (CATER, 1993).

O Estudo da ecologia das paisagens e sua importância para o turismo vem atender algumas das exigências fundamentais no que se refere ao ajustamento do processo ao desenvolvimento sustentável e, principalmente a Qualidade Ambiental das regiões pesquisadas.

O turismo deve ser pautado em um planejamento no qual a conservação ambiental seja o suporte do projeto. Para isso, deve-se promover e incentivar o turismo como uma alternativa de obtenção de recursos para o pagamento da manutenção de locais históricos, arqueológicos e naturais, de forma a não se deteriorarem ou desaparecer. Pode ajudar a manter o meio ambiente agradável como um todo através do controle do ar, da água, da poluição sonora, de problemas com o lixo. Também, pode incentivar a melhoria da estética ambiental por meio de programas de paisagismo, designs adequados de construções e melhor manutenção.

\section{Turismo Rural e sua importância para o desenvolvimento regional}

Uma região agrícola pode estar passando por um processo de estagnação econômica derivado de problemas de mercado ou de desenvolvimento tecnológico. Nessa situação a tendência é a de transformação da agricultura tradicional pela agricultura mecanizada apoiada em grandes latifúndios.

Existem diversas propriedades rurais que possuem belezas naturais pouco conhecidas. Muitas vezes, essas belezas podem se tornar atrações turísticas e gerar benefícios aos produtores e habitantes locais. Surge assim o turismo rural, que consiste em fomentar o atendimento familiar, a recepção dos hóspedes no estilo de vida camponês, na economia e na cultura local, mantendo as fazendas seus métodos tradicionais de produção. Desta forma, a atividade turística pode atuar como um importante fator de valorização de hábitos e costumes relativos ao cotidiano do núcleo receptor frente ao processo de globalização, uma vez que este aspecto é fundamental para caracterizar a diferença entre locais ou regiões. No aspecto econômico o turismo é capaz de aumentar as receitas dos municípios, gerarem impostos, maximizar o recebimento de divisas, gerarem ocupação e renda para a população local e redistribuir a renda.

O surgimento do turismo rural é muito recente como atividade econômica. Este setor se desenvolve a partir de uma oferta gerada pela necessidade de diversificação das atividades desenvolvidas no meio rural, como forma complementar de geração de renda, e em segundo pela demanda de interesse peculiar de alguns turistas, inspirada pela necessidade de volta às origens ou da recuperação do caráter bucólico e aprazível da convivência com a natureza, ou com as práticas tradicionais que não mais se encontram nos grandes centros urbanos.

Em virtude das características das áreas rurais brasileiras, é comum essa mul- 
tiplicidade de atividades turísticas. A identidade de outra atividade vai ocorrer pelo grau de atratividade que ela detenha no produto final. A junção de recursos naturais, da diversificação cultural e das atividades produtivas rurais dá ao turismo rural brasileiro características ímpares. Assim, podemos defini-lo como um produto que atende à demanda de uma clientela turística atraída pela produção e pelo consumo de bens e serviços no ambiente rural produtivo.

O turismo rural é uma atividade agregadora de renda aos produtores rurais, logo, uma das condições necessárias é a de que esse promova sua atividade com Qualidade Ambiental, na propriedade e no entorno desta. Hosken e Viggiano (apud SANTOS, 2004) afirmam que o turismo rural atende a uma clientela turística atraída pela produção e consumo de bens e serviços no ambiente rural produtivo. É um conceito múltiplo de um turismo integrado com natureza, com a maneira de viver da nossa gente, com a aventura e com a região. É uma proposta de respeito às nossas raízes, aos ecossistemas e à nossa identidade cultural; um turismo de aproveitamento da zona rural em toda a sua diversidade.

Já para Coriolano (1998), o turismo rural surge como uma proposta conservacionista, pois é um tipo de turismo que passa a ter cuidado com o meio ambiente, valoriza as populações locais, exige qualidade de vida, hospitalidade, recreação, segurança e serviços inter-relacionados.

Para Campanhola e Silva (1999) o turismo rural é um vetor do desenvolvimento regional ou local, que constitui umas das alternativas mais viáveis para se enfrentar os desafios da globalização. Embora tenda padronizar produtos, padrões de consumo, hábitos e costumes em prol da eficiência e da produtividade, a globalização reforça o local, no sentido de que estimula a organização comunitária, para que encontre o seu caminho de sustentabilidade.

A problemática pesquisada neste estudo foi a geração de resíduos sólidos após a passagem de turistas rurais por um propriedade especialmente preparada para a recepção de turistas no sistema "day use", denominado sítio São Luiz, na localidade de Lomba Grande no município de Novo Hamburgo.

\section{MATERIAIS E MÉTODOS}

Foi realizado um estudo gravimétrico dos resíduos sólidos produzidos no sítio ecológico São Luiz na localidade de Lomba Grande, no município de Novo Hamburgo, em virtude do grande número de turistas que visitam esta propriedade no meio rural.

Foram selecionados 4 finais de semana em que o sítio recebe grande número de turistas. A quantidade de turistas presentes em cada final de semana foi contada através do número de ingressos vendidos. Os resíduos sólidos gerados foram separados nas categorias de matéria orgânica (basicamente restos de alimentos diversos), metais (constituídos quase exclusivamente de latinhas de alumínio), plásticos (de di- 
versas origens, predominando embalagens de Polietileno Tereftalato), papéis (desde papéis convencionais até guardanapos não saturados em gordura) e vidros.

O proprietário do sítio São Luiz não aceita o uso nem a inserção de embalagens de vidro dentro dos domínios da propriedade. A estratégia que aplica é a cobrança de multas junto aos usuários caso sejam identificados materiais vítreos em poder dos turistas. Isto influenciou os resultados obtidos, pois não ocorrem materiais vítreos nos estudos gravimétricos.

Realizou-se a triagem, pesagem e classificação de todo o resíduo sólido gerado na propriedade rural, após a saída dos turistas do empreendimento rural. Os resíduos sólidos foram separados nas categorias acima discriminadas e pesados, gerando médias de consumo per capita de resíduos sólidos em cada uma das datas pesquisadas.

\section{ANÁLISE DOS RESULTADOS}

O sítio São Luiz está localizado na zona rural de Novo Hamburgo em Lomba Grande sendo cercado por morros, mata nativa e as mais belas paisagens do Vale do Rio dos Sinos, situando-se à aproximadamente $50 \mathrm{~km}$ de Porto Alegre.

Dentre os segmentos que desenvolvem o turismo rural, podemos dizer que as propriedades que desenvolvem turismo em áreas rurais têm crescido muito, e o sítio São Luiz é uma destas propriedades que tem se destacado neste segmento. No bairro rural de Lomba Grande predominam empreendimentos que exploram o turismo em áreas rurais. No turismo rural a renda provém predominantemente da produção agropecuária, sendo a presença do turista um agregador de renda na receita total da propriedade.

O objetivo do sítio é oferecer às crianças e adultos maior contato com a natureza e a vida no campo e proporcionar atividades educacionais dirigidas aos estudantes. Há 15 anos o sítio São Luiz vem promovendo atividades com escolas para que tenham a oportunidade de oferecer aos seus alunos aulas práticas em campo, para que em contato com a natureza possam aprender a conhecer, apreciar e proteger 0 meio natural.

O sítio dispõe de várias atrações de lazer para todos os tipos de grupos tais como empresas, igrejas, escoteiros, famílias, escolas e grupos terceira idade. Os visitantes podem passar o dia em locais reservados para cada grupo, com uma programação variada e acompanhada por monitores treinados.

O sítio São Luiz é um empreendimento que trabalha com grupos e possui uma pousada com cerca de 100 camas para hóspedes. O uso da água é extremamente diversificado, servindo para beber, para atividades de limpeza, recreação e funções sanitárias. O uso da água sempre depende do tamanho e do tipo de empreendimento rural a ser explorado. Grandes empreendimentos utilizam grandes quantidades de á- 
gua para manterem seus atrativos, como piscinas e áreas de jardins que necessitam de irrigação.

Stipanuk (apud DEMAJOROVIC; VILELA, 2006) estimam um consumo de 384 litros por quarto/dia em hotéis com menos de 75 quartos. Como os empreendimentos hoteleiros possuem em média duas camas por quarto, o sítio teria em média de 50 quartos, logo necessitaria de 250 litros de água por quarto/dia. Grande parte do consumo de água é dirigido para as ações de saneamento e parte delas se relaciona com a geração de resíduos sólidos.

Um dia de passeio no sítio São Luiz, além de ser prazeroso em suas atividades de lazer, também pode ser muito interessante nos trabalhos desenvolvidos para todas as séries escolares. É uma oportunidade única se desenvolver Educação Ambiental com uma gama de recursos pedagógicos para professores e as mais variadas atividades escolares para as crianças. Sendo um sítio pedagógico, todas as visitas são orientadas por monitores que fornecem uma grande quantidade de informações. Independente da idade do visitante, o sítio São Luiz conta com trabalhos direcionados para aprendizado prático ou empírico.

Por tratar-se de um empreendimento instalado no meio rural, com atividades voltadas a preservação do meio ambiente e com fluxo muito grande de turistas foi 0 escolhido para o estudo do lixo no meio rural para esta pesquisa.

O termo popular "lixo" é o que denominamos normalmente de "resíduos sólidos". Estes materiais que antes eram entendidos como meros subprodutos do sistema produtivo, passam a ser encarados também como responsáveis por graves problemas de degradação ambiental. Os "resíduos sólidos" diferenciam-se do termo "lixo". Lixo se compõe de objetos que não possuem qualquer tipo de valor ou utilidade. São porções de materiais sem significação econômica. Os resíduos sólidos possuem valor econômico agregado por possibilitarem o reaproveitamento através de novo ciclo industrial.

Os resíduos sólidos têm composição extremamente variada, dependendo basicamente da natureza de sua fonte produtora. Também variam qualitativa e quantitativamente com as estações do ano e com as condições climáticas, com os hábitos e o padrão de vida da população (DAROLT et. al., 1996). Podemos dizer que os resíduos sólidos representam o fiel retrato da sociedade que os gera.

A Tabela 1 apresenta um resumo dos estudos gravimétricos sobre geração de resíduos sólidos em turismo ecológico, dentro da concepção de estudo de caso do sítio São Luiz na localidade de Lomba Grande, no município de Novo Hamburgo.

A análise gravimétrica dos resíduos sólidos no sítio escolhido para a medição permite observar que os resíduos sólidos estavam compostos por matéria orgânica constituída de restos de alimentos e material reciclável composto por vidros, latas, papel e plásticos. 
Tabela 1- Quantidade de resíduos gerados pelos turistas, no Sítio São Luiz, em diferentes períodos. Fonte: Kieling 2008

\begin{tabular}{|c|c|c|c|c|c|}
\hline Produto/Datas & $\mathbf{1 1 / 1 2 / 0 7}$ & $\mathbf{0 5 / 0 2 / 0 8}$ & $\mathbf{0 7 / 0 3 / 0 8}$ & $\mathbf{2 3 / 0 3 / 0 8}$ & Totais \\
\hline Total de Turistas & 750 pessoas & 160 pessoas & 140 pessoas & 200 pessoas & 1.250 pessoas \\
\hline Matéria Orgânica & $100 \mathrm{~kg}$ & $30 \mathrm{~kg}$ & $40 \mathrm{~kg}$ & $85 \mathrm{~kg}$ & $255 \mathrm{~kg}$ \\
\hline Metais & $30 \mathrm{~kg}$ & $4,5 \mathrm{~kg}$ & $4 \mathrm{~kg}$ & $20 \mathrm{~kg}$ & $58,5 \mathrm{~kg}$ \\
\hline Plásticos & $7,5 \mathrm{~kg}$ & $5 \mathrm{~kg}$ & $10 \mathrm{~kg}$ & $8 \mathrm{~kg}$ & $30,5 \mathrm{~kg}$ \\
\hline Papéis & $17 \mathrm{~kg}$ & $4 \mathrm{~kg}$ & $6,5 \mathrm{~kg}$ & $9,7 \mathrm{~kg}$ & $37,2 \mathrm{~kg}$ \\
\hline Vidro & $0 \mathrm{~kg}$ & $0 \mathrm{~kg}$ & $0 \mathrm{~kg}$ & $0 \mathrm{~kg}$ & $0 \mathrm{k}$ \\
\hline Totais & $154,5 \mathrm{~kg}$ & $43,5 \mathrm{~kg}$ & $60,5 \mathrm{~kg}$ & $122,7 \mathrm{~kg}$ & $381.2 \mathrm{~kg}$ \\
\hline $\begin{array}{c}\text { Relação } \\
\text { resíduos/por tu- } \\
\text { rista (per capita) }\end{array}$ & $\mathbf{0 , 2 0 6}$ & $\mathbf{0 , 2 7 2}$ & $\mathbf{0 , 4 3 2}$ & $\mathbf{0 , 6 1 3}$ & $\mathbf{0 , 3 0 5}$ \\
\hline
\end{tabular}

A análise gravimétrica dos resíduos sólidos no sítio escolhido para a medição permite observar que os resíduos sólidos estavam compostos por matéria orgânica constituída de restos de alimentos e material reciclável composto por vidros, latas, papel e plásticos.

Dentre as substâncias tóxicas encontradas temos o alumínio; as pilhas e baterias, que lançam níquel e cádmio no ambiente, as lâmpadas que possuem mercúrio, um metal pesado e tóxico que pode contaminar solos e a água.

No sítio São Luiz, estes resíduos são recolhidos em local próprio e depois destinados aos agentes especializados pelo proprietário. Por se tratar de uma propriedade que procura desenvolver e praticar a sustentabilidade, os agentes químicos e agrotóxicos não são utilizados na propriedade, e para melhorar as estruturas do solo são utilizados somente produtos orgânicos e de dejetos animais criados no local.

Conforme quadro, as coletas foram realizadas nas datas acima especificadas em meses alternados e com quantidades variadas de turistas, buscando maior representatividade estatística nos resultados.

A análise permite afirmar que a matéria orgânica guarda correlação direta com o número de pessoas presentes na data da análise e esta diretamente relacionada com restos de alimentos. Os metais representam em geral a quantidade de latas de alumínio para envase de refrigerantes ou cervejas que foi consumida. Os plásticos podem representar restos de sacolas, copos, pratos, garrafas de refrigerantes de Polietileno Tereftalato (PET) e assemelhados. O vidro não está presente porque o sítio São Luiz não permite a entrada deste tipo de vasilhame. Todos os turistas das datas onde foram realizados os levantamentos pertenciam a grupos religiosos.

A Figura 1 apresenta os resíduos sólidos gerados pelos turistas no Sítio São 
Naime, R.; Carvalho, S.

Luiz, nos diferentes períodos analisados.

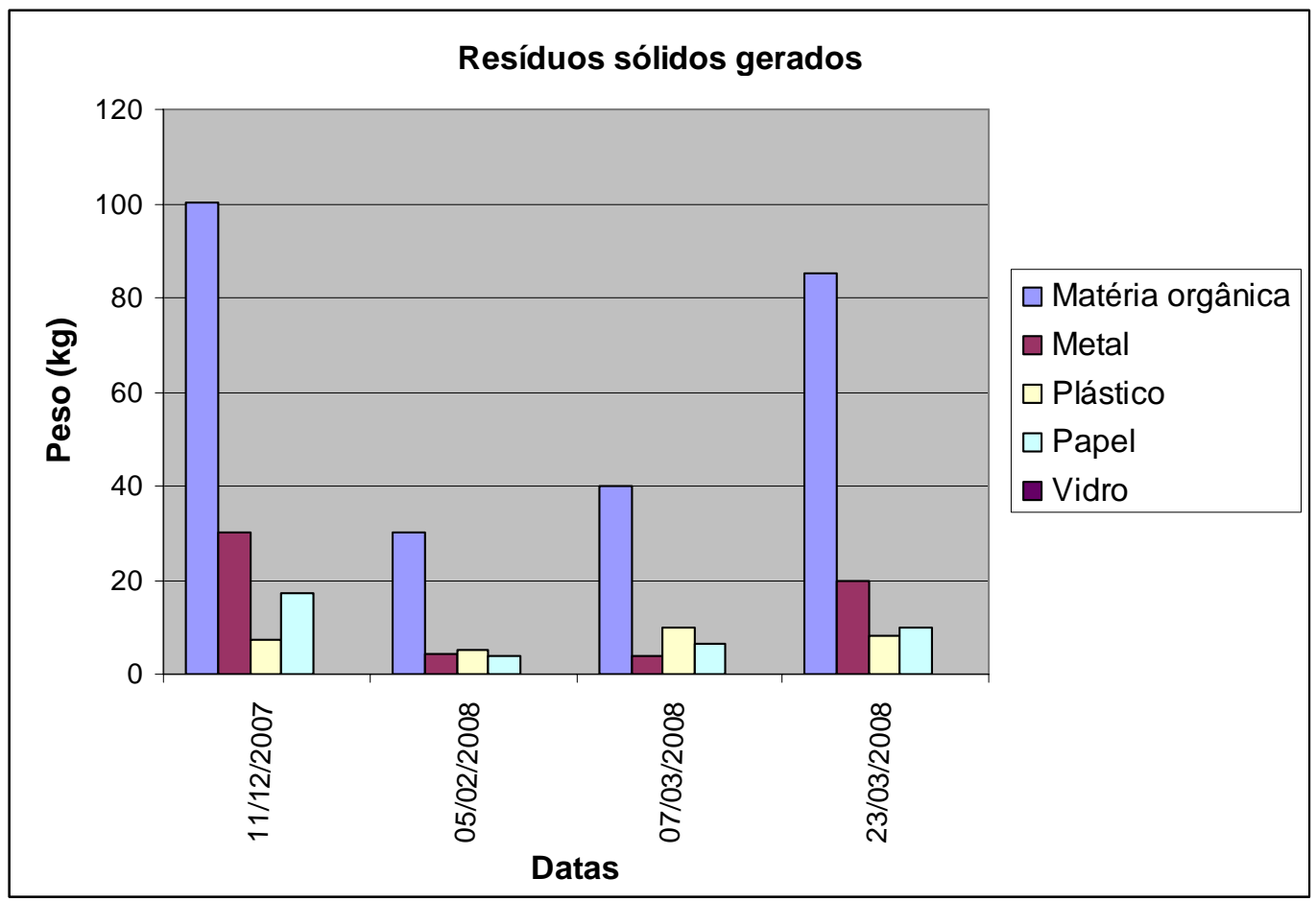

Figura 1 - Resíduos sólidos gerados, em kg, no Sítio São Luiz, nas diferentes datas pesquisadas. Fonte: Kieling, 2008

Conforme visualizamos na figura acima o resíduo de maior peso deixado pelos turistas foi a matéria orgânica, oriunda de restos alimentares (refeições). O segundo resíduo é o de latas, proveniente dos líquidos ingeridos (refrigerantes, cervejas etc). $\mathrm{O}$ papel se encontra como o terceiro resíduo deixado pelos turistas, cabendo salientar que este é oriundo do papel higiênico utilizado nos banheiros, (cada rolo pesa em torno de $0,200 \mathrm{~kg}$ ) e sua quantidade foi obtida pela quantidade de rolos utilizados pelos turistas.

O plástico aparece em quarto lugar em virtude de utilizarmos para a análise a medida em quilogramas, e neste caso, como também foi reciclado, se analisarmos pela quantidade deixada é muito grande, pois foi produzido somente em uma propriedade rural e em quatro finais de semana. $\mathrm{O}$ vidro por ser na opinião do proprietário um dos resíduos mais impactantes para o meio ambiente, este não permite que entre na propriedade (revisa e solicita que os turistas levem junto com eles, pois caso contrário cobra uma taxa adicional de cada um). Na pesquisa o resultado foi zero em virtude da estratégia utilizada pelo proprietário de não admitir o acesso de vasilhames de vidro. 
Na Figura 2 estão apresentadas as médias per capita de produção de resíduos nos dias em que foram realizados os estudos gravimétricos no sítio São Luiz.

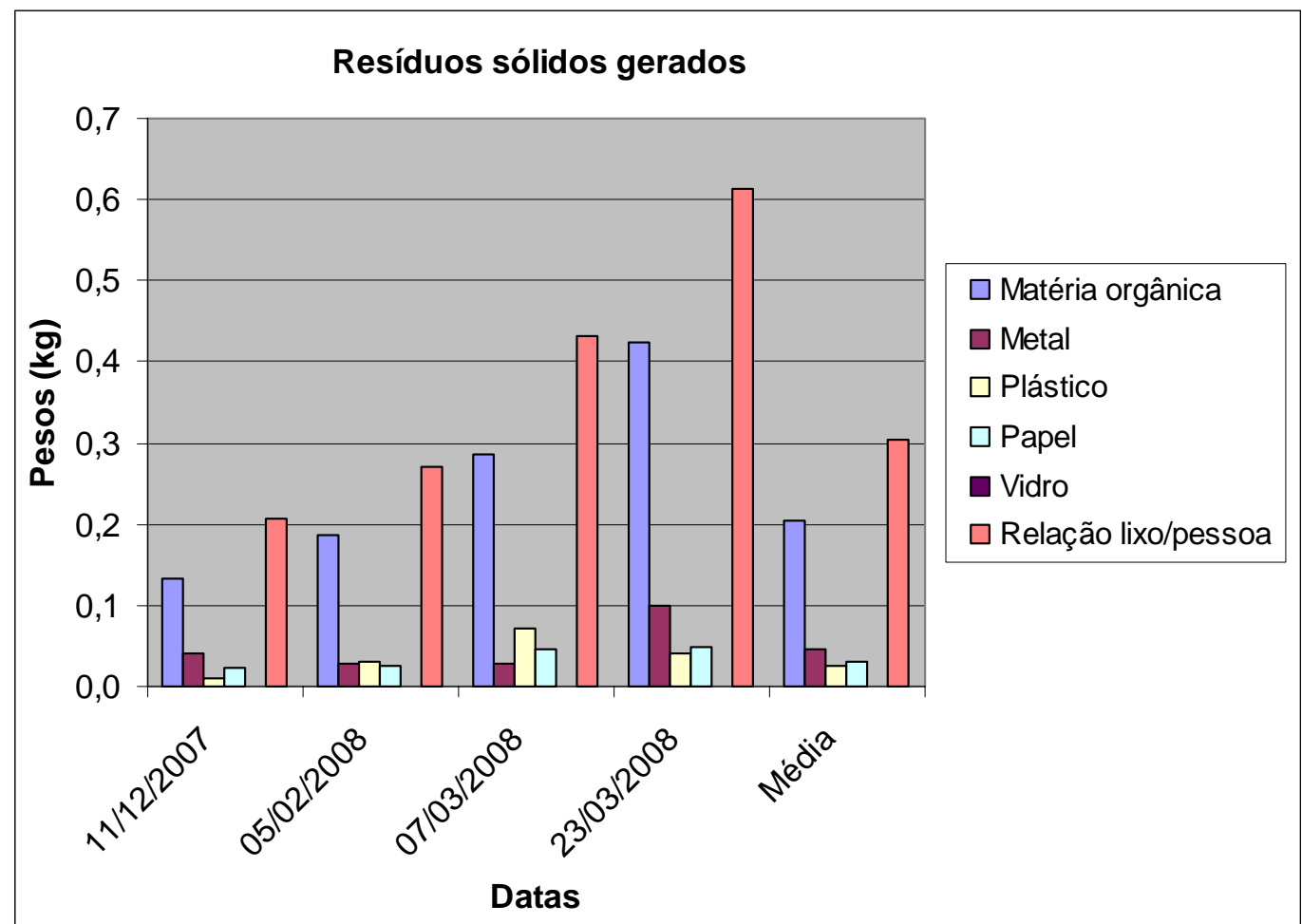

Figura 2 - Número de turistas e resíduos sólidos gerados, em kg/turista, no Sítio São Luiz, em diferentes períodos. Fonte: Kieling, 2008

A produção de matéria orgânica relaciona-se ao número de turistas, idade dos turistas e ao cardápio servido aos turistas na propriedade, e refere-se a restos de comida, deixados como resíduos. Na data de 23/03 a média de matéria orgânica produzida foi muito alta, devido principalmente ao cardápio servido, (churrasco, salada de batata com maionese) e refrigerante, bem como as maiorias de turistas eram compostas por jovens, o que explica a tendência de maior consumo de alimentos. A média encontrada foi de $0,425 \mathrm{~kg}$ de resíduo orgânico/turista/dia. Já a relação de resíduos total foi de 0,614 kg/turista/dia, num universo de 200 turistas, a mais alta de toda a pesquisa.

Na data de 07/03 foi obtida uma média total muito alta também, sendo que o diferencial ficou para o plástico, com muitas garrafas de 2 litros de refrigerantes. A média total foi de 0,432 kg/turistas/dia, sendo de matéria orgânica de 0,286 kg/dia, para um universo de 140 turistas, sendo a maioria de jovens também.

Já nas datas de 05/02 e 11/12 as relações de resíduos orgânicos foram meno- 
Naime, R.; Carvalho, S.

res, 0,188 $\mathrm{kg}$ e 0,133 $\mathrm{kg}$ respectivamente, ficando a média total em 0,272 $\mathrm{kg}$ e 0,206 $\mathrm{kg}$ de resíduos totais por turistas por dia, num universo de 160 e 750 turistas.

A relação de resíduos/pessoas/dia, no município de Novo Hamburgo encontrase em torno de $0,200 \mathrm{~kg} / \mathrm{pessoa} / \mathrm{dia}$ (dado fornecido pela central de reciclagem da Secretaria Municipal de Meio Ambiente e Planejamento Urbano), quase a mesma obtida no dia 11/12 de 2007.

A Figura 3 apresenta a distribuição percentual dos resíduos gerados pelos turistas no Sítio São Luiz, nos diferentes períodos pesquisados.

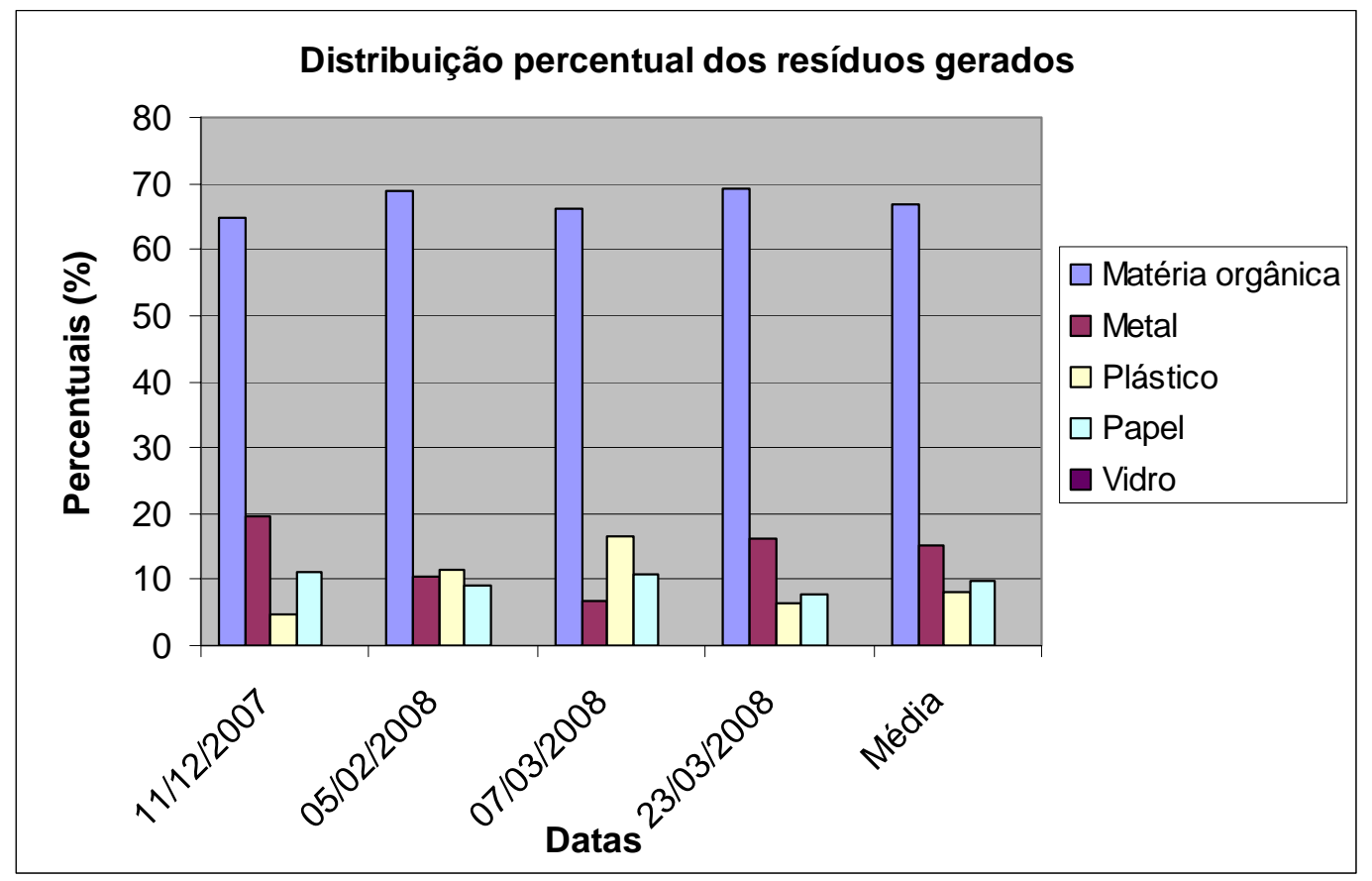

Figura 3 - Distribuição percentual dos resíduos sólidos gerados no Sítio São Luiz, em diferentes períodos. Fonte: Kieling, 2008

$\mathrm{Na}$ análise geral dos resíduos gerados no sítio São Luiz, observamos que a matéria orgânica é a que mais contribui com média de $66,89 \%$, em segundo lugar temos o metal (latas), com 15,35\%, em terceiro lugar o papel com média de 9,76\% e em quarto lugar o plástico com 8,0\%. O vidro não aparece por não ser permitido sua entrada na propriedade.

A propriedade rural estudada aplica um programa de gerenciamento dos resíduos sólidos. A matéria orgânica deixada pelos turistas na propriedade não se constitui um problema, mas sim solução, pois toda a matéria orgânica é levada para compostagem e após utilizada como auxiliar no aumento da fertilidade do solo, tanto para as hortas quanto para as mudas de árvores produzidas pela propriedade. 
O envio de latas de alumínio para a reciclagem permite ao proprietário agregar renda ao sítio, pois troca estes resíduos por churrasqueiras que aluga e materiais empregados na confecção de bancos e demais artefatos. O plástico também é reciclado e enviado para empresas que os reutilizam, não sendo destinado no interior da propriedade.

O único produto que permanece na propriedade são os diversos tipos de papel. Tanto os guardanapos engordurados, como os papéis higiênicos derivados das atividades sanitárias são enterrados em envelopes de argila de baixa permeabilidade para evitar a contaminação dos aqüíferos freático e subterrâneo.

Segundo Naime (2005), gerenciamento ambiental é conjunto de iniciativas para atingir a excelência na gestão de procedimentos relacionados com as questões ambientais. Logo, este deve ser um procedimento que todas as propriedades rurais que desenvolvem o turismo rural devem procurar atender, pois segundo a pesquisa os turistas procuram as propriedades que promovem a gestão ambiental.

O melhor meio para o gerenciamento do lixo ainda é a coleta seletiva, por meio da separação em categorias como vidro, papel, metais e lixo orgânico. Os resíduos sólidos vêm causando grandes preocupações para os governos municipais, na medida em que a sociedade produz mais materiais devido ao excessivo consumo. É inegável o prejuízo causado por estes resíduos sólidos no que se refere às questões sociais e ambientais, além dos indesejáveis efeitos estéticos e sanitários.

Os resíduos sólidos produzidos localmente nas propriedades ou quando atingem cursos de água, ou mesmo pela ação do vento, podem sofrer deslocamentos de quilômetros. Quando não recebem tratamento adequado, os resíduos sólidos constituem um problema sanitário, transmitindo inúmeras doenças, ou servindo de alimento ou abrigo a animais que são vetores de doenças. Além disso, o acúmulo de resíduos sólidos em uma área pode contaminar o solo local e adjacentes, os lençóis freáticos, rios, lagos e mares.

A evidente supremacia dos plásticos em relação aos outros componentes sólidos foi relatada por inúmeros autores em trabalhos semelhantes de diversos países (DEBROT et al, 1999; GARRITY; LEVINGS, 1993; ROSS et al, 1991), e portanto, reflete um padrão mundial. Os plásticos apresentam uma série de características (produção crescente, difícil degradação, fácil dispersão e ampla disseminação) que os fazem hoje, um dos cinco tipos de poluição candidatos a ser alvo de monitoramento permanente em nível mundial (GREGORY, 1999).

Ao material orgânico pode ser aplicado o processo de compostagem decomposição da matéria em que o produto final pode ser aproveitado como adubo orgânico. No caso de aterro sanitário na propriedade o solo deve ser totalmente compactado na base, o que o torna impermeável, evitando assim a penetração do chorume (termo usado para se referir ao líquido escuro e turvo proveniente do armazenamento e repouso do lixo) para os lençóis freáticos. 
O produtor rural não pode esquecer que existe uma correlação direta entre qualidade do meio e qualidade de vida, portanto à medida que o meio ambiente se deteriora, a qualidade de vida é afetada. Desta forma, o gerenciamento da variável ambiental deve, invariavelmente, estar associado a uma estratégia e incremento da produtividade e qualidade, visando minimizar o desperdício de matérias primas, insumos e subprodutos, que além de se constituírem em perdas significativas para a lucratividade das propriedades, agravam concomitantemente os problemas relacionados à depuração de efluentes líquidos e disposição final de resíduos sólidos.

Para finalizar é preciso registrar que o problema do lixo rural ainda é pouco discutido e estudado sendo dedicado poucos recursos específicos para busca de estratégias que minimizem o problema.

Para o proprietário do sítio São Luiz é de fundamental importância à reciclagem do 'lixo' na propriedade, pois além de evitar a ocorrência de impactos ambientais e de

preservar a qualidade ambiental da propriedade, permite ainda agregação de renda com a venda do material reciclado e a utilização da matéria orgânica levada para a produção de compostagem, e posterior utilização de adubo orgânico.

Na pesquisa de geração de resíduos sólidos no sítio São Luiz é essencial destacar as ações de Educação Ambiental praticadas e os processos de gestão dos resíduos sólidos. É estimulada a coleta seletiva e à política dos 3Rs: reduzir, reaproveitar e reciclar os resíduos. No entanto, de uma maneira geral, a ênfase dos programas de coleta está no reaproveitar e no reciclar e não no reduzir o consumo, que se caracteriza como o principal problema.

\section{CONCLUSÕES}

Os resíduos sólidos variam qualitativa e quantitativamente, de acordo com as estações do ano, com as condições climáticas e com os hábitos e o padrão de vida da população (DAROLT et. al., 1996). Os resíduos sólidos gerados são um retrato do estágio da sociedade de consumo que os produz.

A análise deste estudo permite afirmar que a matéria orgânica guarda correlação direta com o número de pessoas presentes na data da análise e esta diretamente relacionada com restos de alimentos.

A propriedade rural estudada aplica um programa de gerenciamento dos resíduos sólidos. A matéria orgânica deixada pelos turistas na propriedade não se constitui um problema, mas sim solução, pois toda a matéria orgânica é levada para compostagem e após utilizada como elemento de fertilização dos solos, tanto para as hortas quanto para as mudas de árvores produzidas pela propriedade.

A remessa das latas de alumínio para a reciclagem permite ao proprietário agregar renda ao sítio, pois troca estes resíduos por churrasqueiras que aluga e materiais empregados na confecção de bancos e demais artefatos. O plástico também é 
reciclado e enviado para empresas que os reutilizam, não sendo destinados no interior da propriedade.

O único produto que permanece no interior da propriedade são os papéis. Tanto guardanapos engordurados como papel higiênico proveniente dos banheiros. Este material é enterrado e se não for protegido adequadamente poderá se constituir em uma contaminação tanto do lençol freático como das águas subterrâneas. O proprietário do sítio deposita estes resíduos em um local com presença de argila de baixa permeabilidade o que permite a inertização deste material.

Com relação aos impactos observados e ou produzidos pela geração de resíduos dos turistas é observado que a preocupação é grande. Os maiores beneficiados pela correta gestão dos resíduos serão tanto os proprietários rurais como os turistas rurais. Logo caberá ao conjunto de envolvidos nas atividades, a conscientização dos impactos provocados quer sejam nas áreas produtivas ou seja dentro das propriedades onde ocorre a geração dos resíduos pelos turistas nos locais visitados como plásticos, papel, vidros e outros (NAIME, 2005).

Atualmente, existe uma insustentabilidade na estrutura socioambiental das cidades e das áreas rurais, tanto nas relações entre as pessoas, como nas relações das pessoas com a natureza. Concordamos com Quintas (2000) que para estas relações serem viáveis, é necessário que haja uma educação integrada no processo de gestão ambiental que proporcione as condições necessárias para a produção e aquisição de conhecimentos e habilidades, e, que desenvolva atitudes, visando à participação individual e coletiva na gestão do uso de recursos ambientais e na concepção e aplicação das decisões que afetam a qualidade dos meios físico-natural e sociocultural.

\section{REFERÊNCIAS BIBLIOGRÁFICAS}

ASHTON; M..S.G; BALSISSERA, R. Turismo em Perspectiva. Novo Hamburgo: Feevale, 2003. $192 \mathrm{p}$.

CAMPANHOLA, C.; SILVA, J. G. Diretrizes de políticas públicas para o novo rural brasileiro: incorporando a noção de desenvolvimento local. In: Congresso Brasileiro de Economia e Sociologia Rural, 37, 1999, Foz do Iguaçu. Anais... Foz do Iguaçu: SoBER, 1999. p.47-57.

CATER, E. Ecotourism in the third world: problems for sustainable tourism development. Tourism Management. Abril,1993, p.85-90.

CORIOLANO, L.N.M.T. Do local ao global: O Turismo Litorâneo Cearense. Campinas: Papiros, 1998, 176p. 
Naime, R.; Carvalho, S.

DAROLT, M.R; DAVANSO, S.M.; LUZ, G.O.F.; MIRANDA, T.L.G.; PENTEADO, P.; PUCCI,A.; RAMINA, R.H.; TREVISAN, E. Percepções Sociológicas de Rotas do lixo reciclado em Curitiba - PR. In: Jornadas Científicas Sobre Meio Ambiente, II. Resumos. Curitiba: UFPR-NIMAD/Grupo Montevideo/UNESCO, 1996.

DEBROT, A. O; TIEL,A. B; BRADSHAW, J. E. Beach debris in Curaçao. Marine Pollution Bulletin 38: (9) pp 795-801 SEP 1999.

FERRETI, E.R. Turismo e Meio Ambiente: Uma Abordagem Integrada - São Paulo: Rocca, 2002, 196p.

GARRITY, S.D.; LEVINGS, S. C. Marine debris along the Caribbean coast of Panama. Elsevier Science, v. 19. n. 3, p. 199-212 1993.

KIELING, R. Qualidade ambiental como fator para o desenvolvimento do turismo rural. Novo Hamburgo, RS: Feevale, 2008. 105 p. Dissertação (Mestrado). Programa de pós-graduação em Qualidade Ambiental, Centro Universitário Feevale, 2008.

NAIME, R. Diagnóstico ambiental e sistemas de gestão ambiental: incluído a atualização da série ISO 9000 e as novas NBR 14001/2004 e NBR ISO 19011/2002 Novo Hamburgo: Feevale, 2005. 168p.

QUINTAS, J.S. (org) - Pensando e praticando a Educação Ambiental na Gestão do meio ambiente. Brasília: IBAMA, 2000.

ROOS, J.B.; PARKER, R.; STRICKLAND, M. A survey of shoreline in Halifax Harbour, Environ Sci Technol.; 24:571-5. 1989.

RUSCHMANN, D. O. O turismo rural e o desenvolvimento sustentável. In: ALMEIDA, J. A.; FROEHLICH, J. M.; RIEDL, M. (org.) Turismo Rural e Desenvolvimento Sustentável. 2. ed. Campinas: Papirus, 2000.

SANTOS, E.O. O Agroturismo e o Turismo Rural em Propriedades da Metade Sul do Estado do Rio Grande do Sul. Porto Alegre: Pallotti, 2004, 147p.

SWARBROOKE, J. Turismo Sustentável. São Paulo: Aleph, 2000, 274p.

VILELA, A.Jr.; DEMAJOROVIC, J. Modelos e ferramentas de gestão ambiental: desafios e perspectivas para as organizações. São Paulo :Editora Senac , 2006.

ZIMMERMANN, A. Turismo Rural: um modelo brasileiro. Florianópolis: Ed. do autor, 1996, 128p. 


\section{AGRADECIMENTOS}

A equipe do Instituto de Ciências Exatas e Tecnológicas (ICET) pelo suporte a este trabalho.

Roberto Naime: Centro Universitário FEEVALE

Email: rnaime@feevale.br

Link para o currículo Lattes: http://lattes.cnpq.br/1800647258153035

Sérgio Carvalho: Universidade Federal de Santa Maria

Email: scarvalho@feevale.br

Link para o currículo Lattes: http://lattes.cnpq.br/9114677690912835

Data de submissão: 15 de abril de 2009

Data do aceite: 13 de agosto de 2009 